\title{
Estrogen suppresses adipogenesis by inhibiting S100A16 expression
}

\author{
Rihua Zhang ${ }^{2, *}$, Dongming $\mathrm{Su}^{3, *}$, Weidong Zhu ${ }^{4,}{ }^{,}$, Qiong Huang ${ }^{1}$, Menglan Liu', Yi Xue ${ }^{6}$, \\ Yuanyuan Zhang', Dong $\mathrm{li}^{5}$, Allan Zhao ${ }^{3}$ and Yun Liu' \\ ${ }^{1}$ Department of Geratology ${ }^{2}$ Laboratory Animal Center, The First Affiliated Hospital ${ }^{3}$ The Center of Metabolism, \\ Nanjing Medical University, Nanjing 210029, China \\ ${ }^{4}$ Department of Urology, Zhongda Hospital Affiliated to Southeast University, Nanjing 210008, China \\ ${ }^{5}$ Department of Orthopedics, Jiangsu Province Hospital of TCM, Affiliated Hospital of Nanjing University of TCM, \\ Nanjing, Jiangsu, China \\ ${ }^{6}$ Department of Endocrinology, Changzhou Wujin People's Hospital, 213000 Changzhou, Jiangsu, China \\ *(R Zhang, D Su and W Zhu contributed equally to this work)
}

Correspondence
should be addressed
to Y Liu
Email
liuyun@njmu.edu.cn

\begin{abstract}
The aim of this study is to determine the effects of $E_{2}$ on metabolic syndrome and the molecular mechanisms involving S100A16. Ovariectomized (OVX) rat models and mouse embryonic fibroblasts cell models were used. $E_{2}$ loss in OVX rats induced body weight gain and central abdominal fat accumulation, which were ameliorated by $E_{2}$ treatment under chow and high-fat diet (HFD) conditions. $E_{2}$ decreased the expression of the adipocyte marker genes PPAR $\gamma$, aP2, CIEBP $\alpha$, and S100A16. $E_{2}$ inhibited adipogenesis. Overexpression of $S 100 A 16$ reversed the $E_{2}$-induced adipogenesis effect. A luciferase assay showed that $E_{2}$ inhibited the expression of S100A16. $E_{2}$ treatment decreased body weight gain and central abdominal fat accumulation under both chow and HFD conditions. Also, $E_{2}$ suppressed adipogenesis by inhibiting S100A16 expression.
\end{abstract}
Key Words
- estrogen
- metabolic syndrome
S100A16

\section{Introduction}

In postmenopausal women, estrogen loss is an independent risk factor for more severe menopausal symptoms, such as metabolic disease, insulin resistance, and type 2 diabetes (Carr 2003, Manrique et al. 2012). Studies on mouse models have shown that oophorectomy results in obesity, altered fat distribution, adipose tissue inflammation, and development of fatty liver (Rogers et al. 2009, Stubbins et al. 2012). Estrogen therapy is believed to have beneficial effects on abdominal fat accumulation, insulin resistance, and development of type 2 diabetes in postmenopausal women (Sørensen et al. 2001, Stubbins et al. 2012). However, there are reports that estrogen treatment does not improve insulin action in humans and rodents (Basu et al. 2007); furthermore, it is associated with a higher risk of insulin resistance and type 2 diabetes in postmenopausal women (Ryan et al. 2002, Ding et al. 2007). The longitudinal data from the Study of Women's Health Across the Nation (SWAN), which included five ethnic groups in the USA - African-Americans, Caucasians, Chinese, Hispanic, and Japanese - indicated that early use of hormone therapy was a risk factor for obesity (Sutton-Tyrrell et al. 2010), and there was little evidence to suggest that estrogen application was beneficial for insulin resistance and stroke (Hu \& Grodstein 2002, 
Golden et al. 2007). Therefore, the relationship between estrogen use and metabolic disorders in postmenopausal women remains controversial. Moreover, the therapeutic effects of estrogen may be influenced by many factors, such as the dosage, the duration of treatment, and the type of estrogen used. Another disadvantage of the clinical application of estrogen is its reported growth-promoting effects on the uterus or mammary gland and tumorpromoting actions (Królik \& Milnerowicz 2012, Nichols et al. 2012). Further studies are therefore needed to re-evaluate the benefits of estrogen treatment and to determine the estrogen dose at which the risk of metabolic diseases is increased.

The mechanisms via which estrogen affects metabolism are complicated and not well known. It is reported that the anti-obesity effect of estrogen depends on leptin and Stat 3 activation (Gao et al. 2007). In our previous study (Liu et al. 2011), we found that a novel adipogenesispromoting factor, the S100A16 protein, which is a member of the $\mathrm{S} 100$ protein family, plays a role in the action of estrogen. We analyzed the S100A16 promoter using AliBaba2 (Grabe 2002), and found four estrogen response elements (EREs) within the 1500-bp promoter region. Therefore, we think that estrogen may regulate lipid metabolism by mediating S100A16 expression.

In this study, we used normal rats and ovariectomized (OVX) rats that received estrogen treatment or control treatment under chow and high-fat diet (HFD) conditions. We wanted to determine which physiological indicators of metabolic disease benefit from estrogen administration, and evaluate the effect of estrogen on S100A16 expression.

\section{Materials and methods}

\section{Animals}

Fifty healthy female specific pathogen-free Sprague-Dawley (SD) rats 6 weeks of age (body weight, 150-200 g) were purchased from and housed at the Experimental Animal Center of Nanjing Medical University (Nanjing, China). The experiments were approved by the Nanjing Medical University Ethical Committee. Animals were housed at $23 \pm 1^{\circ} \mathrm{C}$ with a $12 \mathrm{~h}$ light: $12 \mathrm{~h}$ darkness cycle and $45 \pm 5 \%$ humidity and allowed free access to normal chow diet and water. Thirty-two female SD rats underwent bilateral oophorectomy at the age of 8 weeks under general anesthesia induced with ketamine $(120 \mathrm{mg} / \mathrm{kg}$, i.p.). After 2 weeks of recovery, the rats were allowed free access to water and were fed normal powder chow or HFD. The HFD was supplied by OpenSource DIETS (Research Diets, Inc.,
New Brunswick, NJ, USA, \#D12451). Sixteen OVX rats received s.c. injections (at the back of the neck) of $200 \mu \mathrm{g} / \mathrm{kg}$ 17 $\beta$-estradiol (Sigma, \#E2758) twice a week for 16 weeks. Control rats $(n=16)$ received PBS injections. We measured body weight every week after the first injection.

Three groups of rats were on the chow diet: normal control rats $(n=9)$; OVX rats $(n=8)$; and OVX rats given $\mathrm{E}_{2}$ treatment $(n=8)$. There were also three groups of rats on HFD: normal control rats $(n=9)$; OVX rats $(n=8)$; and OVX rats given $\mathrm{E}_{2}$ treatment $(n=8)$. All procedures were approved by the Experimental Animal Center of Nanjing Medical University.

To assess the effects of $E_{2}$ levels on body weight gain, we monitored the body weight of all rats every week and measured visceral fat weight when the rats were anesthetized with Nembutal $(100 \mathrm{mg} / \mathrm{kg})$. All protocols involving the use of animals have been approved by the Institutional Animal Care and Use Committee (IACUC) at the University of Nanjing Medical University. In addition, we investigated the morphology of visceral fat cells from all rats fed normal chow and HFD by using hematoxylin and eosin staining.

\section{Intraperitoneal glucose tolerance test}

Fourteen weeks after the $\mathrm{E}_{2}$ treatment, IPGTT was conducted. All rats were starved for $12 \mathrm{~h}$, and then their tail blood glucose concentrations $(\mathrm{mM})$ were monitored using a handheld glucometer (ACCU-CHEK Performa, Roche). Blood was collected from the inner canthus to detect insulin concentration. Next, all rats received i.p. injections of glucose $(2 \mathrm{~g} / \mathrm{kg}$ body weight); tail blood glucose concentrations were measured using the handheld glucometer and blood was collected from the inner canthus at $15,30,60$, and $120 \mathrm{~min}$. Blood samples were analyzed for insulin at every time point using an immunoradiometric assay kit (\#KAP1251) supplied by DIAsource ImmounoAssays S.A (Louvain-La-Neuve, Belgium).

\section{Measurement of $E_{2}$ and liver and kidney function indicators}

At the end of 16 weeks of $E_{2}$ treatment, all rats were anesthetized with ketamine $(120 \mathrm{mg} / \mathrm{kg}$ i.p.), and blood was collected by cardiac puncture from the left ventricle into tubes precoated with potassium-EDTA, and centrifuged at $3000 \mathrm{~g}$ and $4{ }^{\circ} \mathrm{C}$ for plasma preparation. The plasma concentrations of $\mathrm{E}_{2}$ were quantified using immunoradiometric assay kits supplied by DIAsource ImmounoAssays S.A. (\#KIP0629). The plasma levels of

Published by Bioscientifica Ltd 
total cholesterol (TC), triglyceride (TG), LDL, HDL, alanine transaminase (ALT), lactate dehydrogenase (LDH), creatinine $(\mathrm{Cr})$, urea, and uric acid (UA) were determined by the Medical Laboratory of Jiangsu Province Hospital, The First Affiliated Hospital of Nanjing Medical University. All assays were performed according to the manufacturer's instructions.

Visceral fat was removed rapidly; part of the samples was frozen in liquid $\mathrm{N}_{2}$ and stored at $-80{ }^{\circ} \mathrm{C}$ for the extraction of protein, and part of the samples was formalin fixed and paraffin embedded for the production of pathological sections. The same procedure was performed on the rest of the tissues.

\section{Mouse embryonic fibroblast isolation and differentiation}

Mouse embryonic fibroblasts (MEFs) were isolated from the embryos of C57BL/6 and S100A16 ${ }^{\mathrm{Tg}+/+}$ mice at 13.5 days post coitum. The construct was generated by inserting S100A16 cDNA into a vector with the PCAG promoter. We then obtained transgenic mice by the microinjection method. This F0 transgenic mouse was bred with the C57BL/6 mouse to obtain F1 transgenic mouse lines. S100A16-positive transgenic mice and their genotype were confirmed by PCR, and the expression of S100A16 was determined by qPCR and western blot. Embryos were chopped and incubated in a $0.25 \%$ trypsin and $0.01 \%$ EDTA solution at $37^{\circ} \mathrm{C}$ for $10 \mathrm{~min}$. The cells dispersed by pipetting were washed with PBS and then maintained in DMEM (Gibco) containing 10\% fetal bovine serum (FBS) (Hyclone, Thermo Scientific, Logan, UT, USA), $100 \mathrm{U} / \mathrm{ml}$ penicillin, and $0.1 \mathrm{mg} / \mathrm{ml}$ streptomycin in a $5 \% \mathrm{CO}_{2}$ atmosphere at $37^{\circ} \mathrm{C}$. To induce adipocyte differentiation, 2-day post-confluent MEFs (designated day 0) were cultured with DMEM containing $10 \%$ FBS and MIX (0.5 mmol/1 3-isobutyl-1-methyxanthine, $1 \mu \mathrm{g} / \mathrm{ml}$ porcine insulin, and $1 \mathrm{mmol} / \mathrm{l}$ dexamethasone (Sigma)). After $48 \mathrm{~h}$ of incubation (designated day 2), the medium was replaced with DMEM containing $10 \% \mathrm{FBS}$ and $1 \mu \mathrm{g} / \mathrm{ml}$ insulin.

\section{Oil Red O staining}

Differentiated MEFs (day 10) were washed three times with PBS and stained with filtered Oil Red O solution (stock solution, $3 \mathrm{mg} / \mathrm{ml}$ in isopropanol; working solution, $60 \%$ of the stock solution and $40 \%$ distilled water) for $30 \mathrm{~min}$ at room temperature. The cells were then washed with $\mathrm{ddH}_{2} \mathrm{O}$ to remove unbound dye, visualized, and photographed under a microscope.

\section{TG GPO-POD assay}

Cellular TG content was determined using a TG GPO-POD assay kit (Sigma). MEFs were cultured and induced in a $10-\mathrm{cm}$ well by MIX to differentiate into adipocytes (10 days), washed with PBS twice, scraped into $500 \mu \mathrm{l}$ PBS, sonicated to homogenize the suspension, and then assayed for total TG content.

\section{Protein extraction and western blotting}

Tissues and cells were washed twice with ice-cold PBS. Then, $100 \mathrm{mg}$ tissue was lysed with $1 \mathrm{ml}$ lysis buffer (50 mM Tris- $\mathrm{HCl}$ (pH 7.4), $150 \mathrm{mM} \mathrm{NaCl}, 1 \%(\mathrm{v} / \mathrm{v})$ Nonidet-P40, $1 \mathrm{mM}$ EDTA, $1 \mathrm{mM} \mathrm{NaF}, 10 \mu \mathrm{g} / \mathrm{ml}$ aprotinin, $10 \mu \mathrm{M}$ leupeptin, and $1 \mathrm{mM}$ phenylmethanesulfonyl fluoride). The cells were scraped into the lysis buffer, and then tissues and cells were allowed to stand on ice for $30 \mathrm{~min}$. After centrifugation at $4{ }^{\circ} \mathrm{C}$, the proteins in the supernatant were extracted and separated on SDS-polyacrylamide gels before being subjected to a standard western blot assay and imaged using Molecular Imager ChemiDoc XRS + with the Image Lab Software (Version 4.0.1, Bio-Rad Laboratories, Hercules, CA, USA).

\section{Luciferase assay}

Luciferase reporter plasmid construction. The S100A16 promoter $(1500 \mathrm{bp})$ was amplified by PCR using primers terminating in an XhoI and HindIII recognition sequence. The PCR product was digested and ligated into a pGL3-basic vector.

Transient transfection and luciferase assay. The day before transfection, $\mathrm{CHO}$ cells were plated on 12-well cell culture plates at $3 \times 10^{5}$ cells/well. Transfection was performed using the X-tremeGENE HP DNA Transfection Reagent (\#06365752001, Roche), following the manufacturer's protocol. Six hours later, cells were treated with $\mathrm{E}_{2}$ $(400 \mathrm{pg} / \mathrm{ml})$ and/or tamoxifen $(0.05 \mu \mathrm{M})$ for $24 \mathrm{~h}$. The Renilla luciferase reporter plasmid pRL-SV40 was used as an internal control. Luciferase activity was measured using the dual luciferase assay system (Promega, E1910) with a luminometer (GloMax 20/20 Luminometer, Promega (Turner)). Luciferase assays were performed in triplicate and repeated at least three times to confirm their reproducibility.

\section{Statistical analyses}

The in vitro and in vivo results were analyzed using one-way ANOVA. $P<0.05$ was considered to indicate statistical significance. The results are presented as mean \pm s.D. of the values from three to six replicates per group.

Published by Bioscientifica Ltd 


\section{Results}

The effect of $E_{2}$ on body weight gain, visceral fat weight, and biochemical traits under both the chow and HFD conditions

We measured $\mathrm{E}_{2}$ concentrations at the time the animals were killed. Under the chow conditions, in comparison to the control rats, $\mathrm{E}_{2}$ concentrations increased in the OVX rats treated with $\mathrm{E}_{2}(759.11 \pm 53.22 \mathrm{vs} 77.09 \pm 5.21 \mathrm{pg} / \mathrm{ml})$ and decreased in the OVX rats not treated with $\mathrm{E}_{2}(42.0 \pm$ 3.02 vs $77.09 \pm 5.21 \mathrm{pg} / \mathrm{ml}$ ); also under the HFD conditions, $\mathrm{E}_{2}$ concentrations increased in the OVX rats treated with $\mathrm{E}_{2} \quad(1209.08 \pm 198.02$ vs $100.82 \pm$ $14.09 \mathrm{pg} / \mathrm{ml}$ ) and decreased in the OVX rats not treated with $\mathrm{E}_{2}(34.0 \pm 3.15$ vs $100.82 \pm 14.09 \mathrm{pg} / \mathrm{ml})$ (Table 1$)$.

Under the chow and HFD conditions, the high level of $\mathrm{E}_{2}$ was more efficacious at lowering the percentage of body weight gain and visceral fat weight than control treatment. Under both diet conditions, low levels of $\mathrm{E}_{2}$ had the opposite effect. Under the chow conditions, the percentage of body weight gain was $5.32 \%$ in the high- $\mathrm{E}_{2}$ group, $61.40 \%$ in the low- $\mathrm{E}_{2}$ group, and $40.62 \%$ in the control group. Visceral fat weight was $4.7 \pm 0.91 \mathrm{~g}$ in the high- $\mathrm{E}_{2}$ group, $35.1 \pm 1.83 \mathrm{~g}$ in the low- $\mathrm{E}_{2}$ group, and $20.8 \pm 1.75 \mathrm{~g}$ in the control group (Table 1 ). Under the HFD conditions, the percentage of body weight gain was $8.25 \%$ in the high$\mathrm{E}_{2}$ group, $64.71 \%$ in the low- $\mathrm{E}_{2}$ group, and $38.23 \%$ in the control group. Visceral fat weight was $12.06 \pm 1.04 \mathrm{~g}$ in the high- $\mathrm{E}_{2}$ group, $42.8 \pm 2.14 \mathrm{~g}$ in the low- $\mathrm{E}_{2}$ group, and $31.3 \pm 2.06 \mathrm{~g}$ in the control group (Table 1 ).

Under both diet conditions, the size of visceral fat cells was decreased in the $\mathrm{E}_{2}$-treated OVX rats, and it was increased in the OVX rats. These results were similar to the body weight changes and confirm that $\mathrm{E}_{2}$ inhibited body weight gain (Fig. 1A).

The plasma levels of TC and TGs increased in OVX rats, and returned to normal levels with $\mathrm{E}_{2}$ treatment under both conditions (Table 2). There were no changes in HDL and LDL levels under these conditions. which was decreased using $\mathrm{E}_{2}$ treatment in the two conditions (Table 2)
The levels of ALT and LDH, which are common biomarkers for liver damage, were determined in plasma samples. Under both conditions, the level of ALT and LDH were increased, which were reduced by $\mathrm{E}_{2}$ treatment (Table 3). Morphological analysis of liver cells showed that compared with chow-fed rats, the livers of rats fed HFD appeared to be filled with macrovesicular fat within the hepatocytes. Importantly, $\mathrm{E}_{2}$ treatment reduced lipid accumulation in the liver under both conditions (Fig. 1B).

The plasma levels of UA in the OVX group was increased but the difference was not significant. Whilst the levels for the $\mathrm{E}_{2}$-treated OVX group were lower than those for the OVX group, in the HFD group the levels were higher than in the control group and in the Chow group the levels were lower. Both these differences were significant, implying that the $\mathrm{E}_{2}$-treated groups differed from the control group in opposite directions (Table 3).

\section{The effect of $E_{2}$ on systemic glucose homeostasis}

The effect of $\mathrm{E}_{2}$ on systemic glucose homeostasis was evaluated by the IPGTT. Under the chow conditions, blood glucose reached its maximum at $15 \mathrm{~min}$ in all rats. Interestingly, the maximum blood glucose level was $53.3 \pm 4.3$ and $54.7 \pm 3.2 \mathrm{mM}$ in the normal and OVX rats, respectively, but only $28.4 \pm 2.3 \mathrm{mM}$ in the OVX rats treated with $\mathrm{E}_{2}$. Subsequently, the blood glucose level gradually decreased in all rats. Importantly, the blood glucose of control and OVX rats treated with $\mathrm{E}_{2}$ dropped to low levels at $120 \mathrm{~min}$, but the blood glucose of the OVX rats not treated with $\mathrm{E}_{2}$ was higher than physiological concentrations at $120 \mathrm{~min}(32.2 \pm 2.2$ vs $6.1 \pm 1.1 \mathrm{mM}$; Fig. 2A). The OVX rats had already become glucoseintolerant at this time. When compared with control rats, glucose-stimulated insulin secretion was abolished and insulin concentration remained low in the OVX rats but not $\mathrm{E}_{2}$-treated OVX rats (Fig. $2 \mathrm{~B}$ ).

Under the HFD conditions, blood glucose reached its maximum at $30 \mathrm{~min}$ in normal and OVX rats, at $88.6 \pm 7.7$ and $87.2 \pm 6.5 \mathrm{nM}$, respectively, but the maximum was

Table $1 E_{2}$ inhibited body weight gain and visceral fat weight increase under both the chow and the HFD conditions. Plasma concentration of $E_{2}$, body weight gain, and visceral fat weight in the different groups of rats. Results are expressed as mean \pm s.D.

\begin{tabular}{|c|c|c|c|}
\hline \multirow[b]{2}{*}{ Diet } & \multicolumn{3}{|c|}{ Plasma $E_{2}(p g / m l)$} \\
\hline & Normal & OVX & $\mathrm{OVX}+\mathrm{E}_{2}$ \\
\hline $\begin{array}{l}\text { Chow } \\
\text { HFD }\end{array}$ & $\begin{array}{c}77.09 \pm 5.21 \\
100.82 \pm 14.09\end{array}$ & $\begin{array}{l}42 \pm 3.02 * \\
34 \pm 3.15^{*}\end{array}$ & $\begin{array}{c}759.11 \pm 53.22 * \\
1209.08 \pm 198.02 *\end{array}$ \\
\hline
\end{tabular}

\begin{tabular}{|c|c|c|}
\hline \multicolumn{3}{|c|}{ Body weight gain (\%) } \\
\hline Normal & OVX & $\mathrm{OVX}+\mathrm{E}_{2}$ \\
\hline $\begin{array}{l}40.62 \pm 5.27 \\
38.23 \pm 5.03\end{array}$ & $\begin{array}{l}61.40 \pm 5.33^{*} \\
64.71 \pm 6.24^{*}\end{array}$ & $\begin{array}{l}5.32 \pm 1.01 * \\
8.25 \pm 0.15^{*}\end{array}$ \\
\hline
\end{tabular}

\begin{tabular}{|c|c|c|}
\hline \multicolumn{3}{|c|}{ Visceral fat weight (g) } \\
\hline Normal & OVX & $\mathrm{OVX}+\mathrm{E}_{2}$ \\
\hline $\begin{array}{l}20.8 \pm 1.75 \\
31.3+2.06\end{array}$ & $\begin{array}{l}35.1 \pm 1.83^{*} \\
42.8+2.14^{*}\end{array}$ & $\begin{array}{c}4.7 \pm 0.91 * \\
12.06+1.04 \text { * }\end{array}$ \\
\hline
\end{tabular}

${ }^{\star} P<0.05$ compared with the corresponding control group. OVX, ovariectomized; HFD, high-fat diet; $E_{2}$, estrogen.

http://jme.endocrinology-journals.org DOI: 10.1530/JME-13-0273
C 2014 The authors Printed in Great Britain
Published by Bioscientifica Ltd 
A

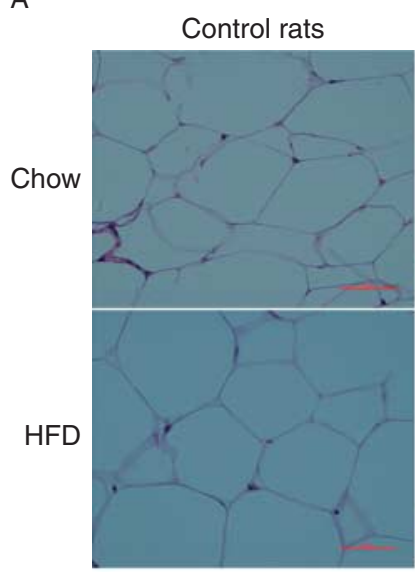

B

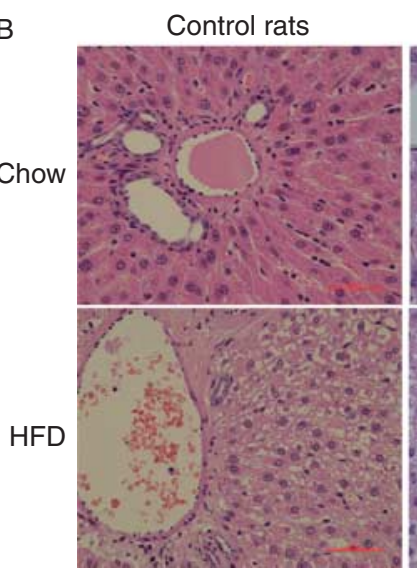

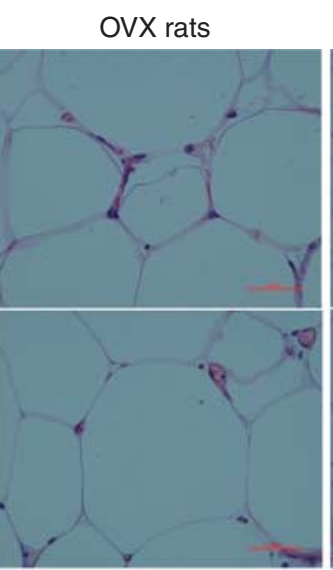

OVX rats

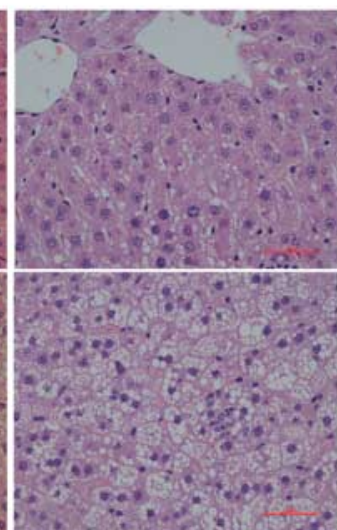

OVX rats treated with $\mathrm{E}_{2}$

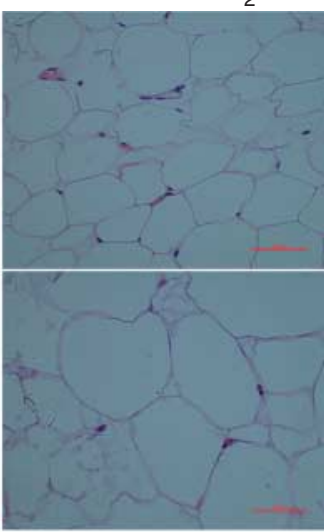

OVX rats treated with $\mathrm{E}_{2}$

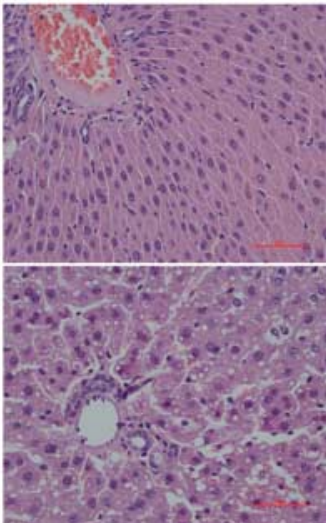

\section{Figure 1}

Images of visceral fat cells and liver cells. (A) Images of visceral fat cells after hematoxylin and eosin (HE) staining. The body weights of all rats were monitored every week and visceral fat weight was measured when the mice were anesthetized with Nembutal $(100 \mathrm{mg} / \mathrm{kg})$. The images are shown

$71.1 \pm 4.3 \mathrm{nM}$ at $15 \mathrm{~min}$ in the OVX rats treated with $\mathrm{E}_{2}$. The blood glucose of the normal and the OVX rats decreased but did not drop to normal levels $(42.2 \pm 3.1$ vs $6.1 \pm 1.1 \mathrm{nM})$. The blood glucose of the OVX rats treated with $\mathrm{E}_{2}$ dropped to close to the normal levels, at 20.4土 $5.7 \mathrm{nM}$ at $120 \mathrm{~min}$ (Fig. 2C). Glucose-stimulated insulin secretion was abolished and insulin concentration remained low in the OVX rats but not $\mathrm{E}_{2}$-treated OVX at $400 \times$ magnification. (B) Histological images of the livers of rats fed chow and HFD, as visualized by HE staining. All the images are shown at $400 \times$ magnification.

rats (Fig. 2D). The OVX rats had already become glucoseintolerant at this time.

\section{The effect of $E_{2}$ on the expression of adipogenesis marker genes $P P A R \gamma, C / E B P \alpha$, and aP2 in fat tissues}

Differentiation of preadipocytes to adipocytes requires coordinated action of a large repertoire of transcription

Table 2 The effect of $E_{2}$ on TC, TG, LDL, and HDL under both the chow and the HFD conditions. Plasma level of TC, TGs, LDL, and $\mathrm{HDL}$ in the different groups of rats. Results are expressed as mean \pm s.D.

\begin{tabular}{|c|c|c|c|c|c|c|c|c|c|c|c|c|}
\hline \multirow[b]{2}{*}{ Diet } & \multicolumn{3}{|c|}{ TC $(\mathrm{mmol} / \mathrm{l})$} & \multicolumn{3}{|c|}{ TG $(\mathrm{mmol} / \mathrm{l})$} & \multicolumn{3}{|c|}{ LDL (mmol/l) } & \multicolumn{3}{|c|}{ HDL (mmol/l) } \\
\hline & Normal & OVX & $\mathrm{OVX}+\mathrm{E}_{2}$ & Normal & OVX & $\mathrm{OVX}+\mathrm{E}_{2}$ & Normal & OVX & $\mathrm{OVX}+\mathrm{E}_{2}$ & Normal & OVX & $\mathrm{OVX}+\mathrm{E}_{2}$ \\
\hline $\begin{array}{l}\text { Chow } \\
\text { HFD }\end{array}$ & $\begin{array}{l}2.16 \pm 0.16 \\
2.23 \pm 0.27\end{array}$ & $\begin{array}{r}2.84 \pm 0.09 * \\
3.3 \pm 0.15^{*}\end{array}$ & $\begin{array}{l}2.18 \pm 1.12 * \\
2.32 \pm 0.29 *\end{array}$ & $\begin{array}{l}0.67 \pm 0.26 \\
1.11 \pm 0.08\end{array}$ & $\begin{array}{l}1.01 \pm 0.18^{*} \\
1.59 \pm 0.18^{*}\end{array}$ & $\begin{array}{l}0.56 \pm 0.1 \text { * } \\
1.09 \pm 0.11 \text { * }\end{array}$ & $\begin{array}{l}0.23 \pm 0.14 \\
0.17 \pm 0.09\end{array}$ & $\begin{array}{l}0.39 \pm 0.08 \\
0.29 \pm 0.08\end{array}$ & $\begin{array}{l}0.19 \pm 0.07 \\
0.17 \pm 0.12\end{array}$ & $\begin{array}{l}1.43 \pm 0.14 \\
1.44 \pm 0.09\end{array}$ & $\begin{array}{l}1.67 \pm 0.08 \\
1.41 \pm 0.08\end{array}$ & $\begin{array}{r}1.5 \pm 0.07 \\
1.36 \pm 0.12\end{array}$ \\
\hline
\end{tabular}

${ }^{*} P<0.05$ compared with the corresponding control group. TC, total cholesterol; TGs, triglycerides; OVX, ovariectomized; HFD, high-fat diet; $E_{2}$, estrogen.

$\begin{array}{lr}\text { http://jme.endocrinology-journals.org } & \text { ( } 2014 \text { The authors } \\ \text { DOI: } 10.1530 / J M E-13-0273 & \text { Printed in Great Britain }\end{array}$

Published by Bioscientifica Ltd 


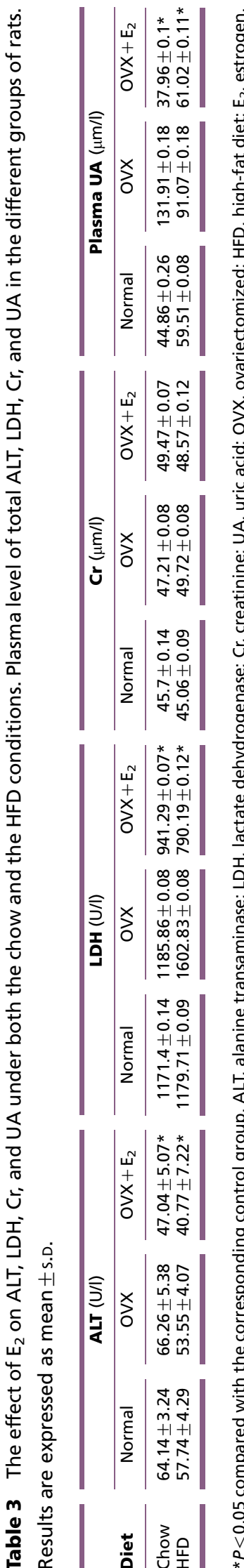

http://jme.endocrinology-journals.org DOI: 10.1530/JME-13-0273 factors, such as PPAR,$C / E B P \alpha$, and aP2. S100A16 is a novel adipogenesis-promoting factor. In order to study the mechanism of $E_{2}$-suppression of body weight gain, we detected the expression of these proteins in the fat tissue of all groups. According to the results of western blotting, the expression of $S 100 A 16, P P A R \gamma, C / E B P \alpha$, and aP2 was significantly elevated in fat tissues from non-treated OVX rats fed chow or HFD. In sharp contrast to these observations, these proteins only showed a slight increase in the fat tissues from OVX rats treated with $\mathrm{E}_{2}$ under both conditions (Fig. 3A, B, C, D, E, F, G and H).

\section{The role of S100A16 in $E_{2}$-induced suppression of adipogenesis}

When compared with control cells, $\mathrm{E}_{2}$-treated S100A $16^{\mathrm{Tg}+/+}$ MEFs (preadipocytes) showed a significant decrease in S100A16 expression in a dose-dependent manner (Fig. 4A and C). Stimulation of S100A16 $6^{\mathrm{Tg}+/+}$ MEFs with $100 \mathrm{pg} / \mathrm{ml} \mathrm{E}_{2}$ (Fig. $4 \mathrm{~B}$ and D) showed a significant change in S100A16 protein expression after $24 \mathrm{~h}$. Therefore, $\mathrm{E}_{2}$ inhibited S100A16 expression in a dose- and time-dependent manner. We also detected the effect of $\mathrm{E}_{2}$ on endogenous S100A16 expression using normal MEFs from C57BL/6 mice. The results indicated that $\mathrm{E}_{2}$ inhibited S100A16 expression (Fig. $4 \mathrm{E}$ and F). We examined the effect of $\mathrm{E}_{2}$ on the levels of S100A16 mRNA in normal MEFs and S100A16 $6^{\mathrm{Tg}+/+}$ MEFs. The results showed that $\mathrm{E}_{2}$ suppressed the S100A16 mRNA expression in normal MEFs, but had no effect on the S100A16 mRNA expression in S100A16 ${ }^{\mathrm{Tg}+/+}$ MEFs (Fig. $4 \mathrm{G}$ and $\mathrm{H}$ ).

To confirm whether $\mathrm{E}_{2}$ suppressed adipogenesis by inhibiting the expression of S100A16, MEFs isolated from S100A16 $6^{\mathrm{Tg}+/+}$ and $\mathrm{C} 57 \mathrm{BL} / 6$ mice were treated with different concentrations of $\mathrm{E}_{2}$ and stained with Oil Red $\mathrm{O} . \mathrm{E}_{2}$ treatment resulted in sparse staining, which was ameliorated by the overexpression of S100A16 (Fig. 4I). Consistent with the staining patterns, quantitative analysis of cellular TGs showed that TG accumulation was significantly lower in the C57BL/6 MEFs treated with $\mathrm{E}_{2}(400 \mathrm{pg} / \mathrm{ml})$ than the S100A16 $6^{\mathrm{Tg}+/+}$ cells (Fig. 4J). The results indicate that overexpression of S100A16 reversed reduction of TG accumulation induced by $\mathrm{E}_{2}$.

\section{Effect of $E_{2}$ on S100A16 transcription}

We predicted the transcription factors that may bind to the promoter region of S100A16, using bioinformatics (http://www.cbrc.jp/htbin/nph-tfsearch). The S100A16 promoter has numerous transcription factor-binding

Published by Bioscientifica Ltd 
A
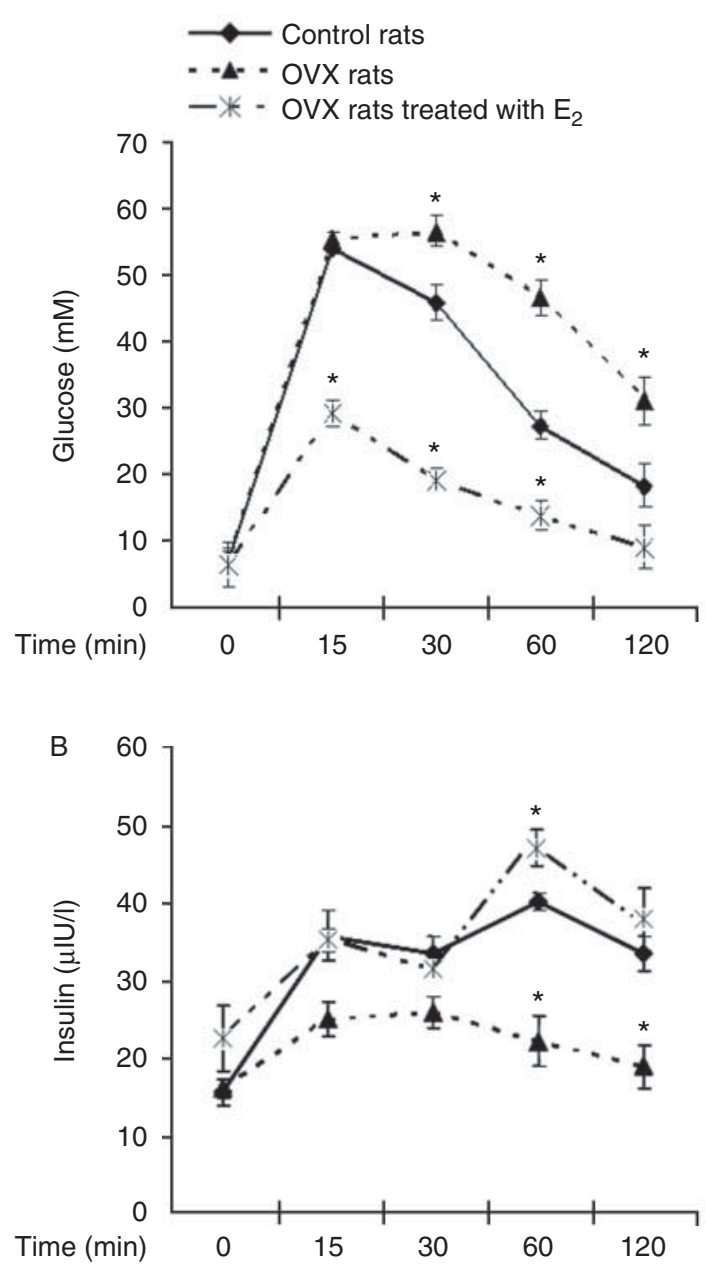

C
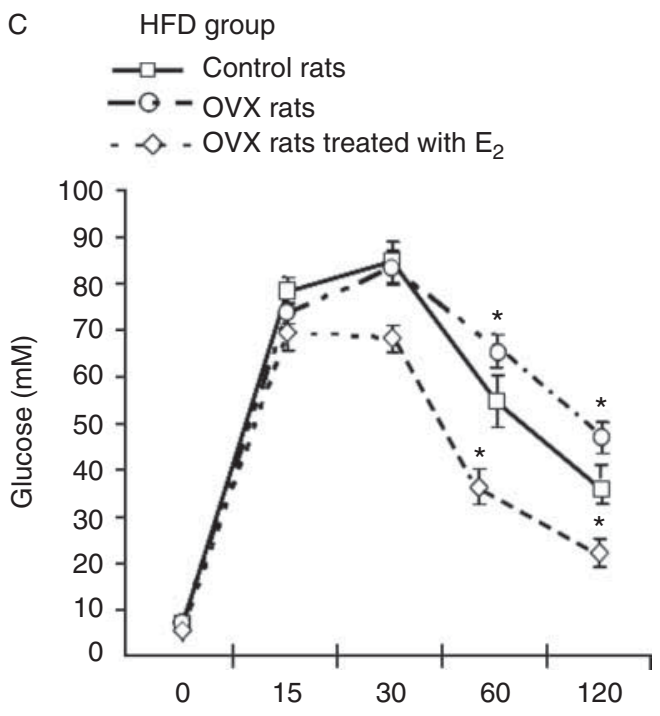

D

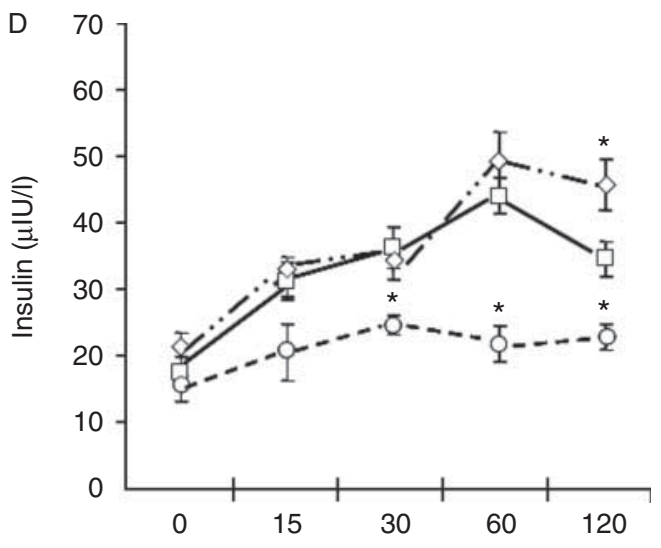

Figure 2

The effect of $E_{2}$ on systemic glucose homeostasis. (A) Glucose level of rats under the chow conditions. (B) Insulin level of rats under the chow conditions. (C) Glucose level of rats under the HFD conditions. (D) Insulin level of rats under the HFD conditions. Results are expressed as the mean \pm s.D. ${ }^{*} P<0.05$ compared with the corresponding control group.

sites, and also four estrogen receptor (ER)-binding sites (Fig. 5A).

The 1.44-kb upstream region of mouse S100A16 was constructed into a luciferase reporter (pGL3-basic). In $\mathrm{CHO}$ cells, $\mathrm{E}_{2}$ reduced the transactivation of this reporter, which was partly reversed by tamoxifen (an inhibitor of ER; Fig. 5B). The data indicated the possibility that $\mathrm{E}_{2}$ inhibited S100A16 expression, at least in part, by acting as a negative transcriptional regulator of S100A16.

\section{Discussion}

In the present study, we studied the effect of different estrogen dosages on weight gain, insulin sensitivity, glucose and lipid metabolism, differentiation of MEFs, and liver and renal function in OVX and control female rats fed chow and HFD.

Our data indicated that estrogen depletion induced body weight gain and central abdominal fat accumulation, which were ameliorated by estrogen therapy under both diet conditions (Table 1). We also found that $\mathrm{E}_{2}$ loss induced glucose metabolism disorder and insulin resistance under different diet conditions (Fig. 2), and subsequently led to the development of metabolic syndrome. This is in agreement with results of studies which showed that $\mathrm{E}_{2}$ loss was positively associated with insulin resistance (Kalish et al. 2003). The features of the metabolic syndrome are related to the accumulation of visceral adiposity, insulin resistance, and disorder of biomarkers of liver and kidney. Although high amounts 


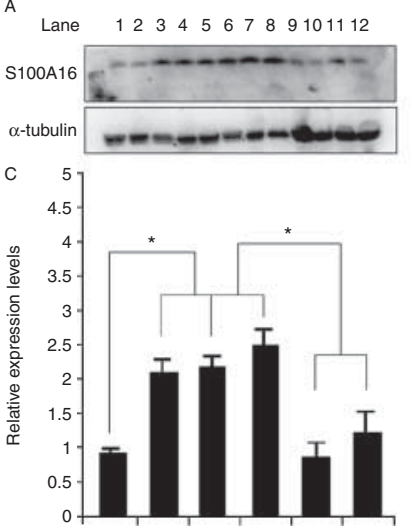

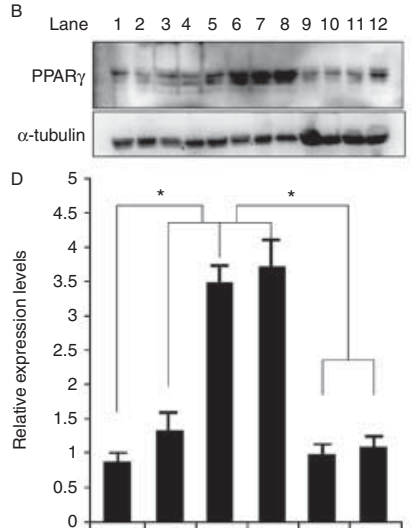
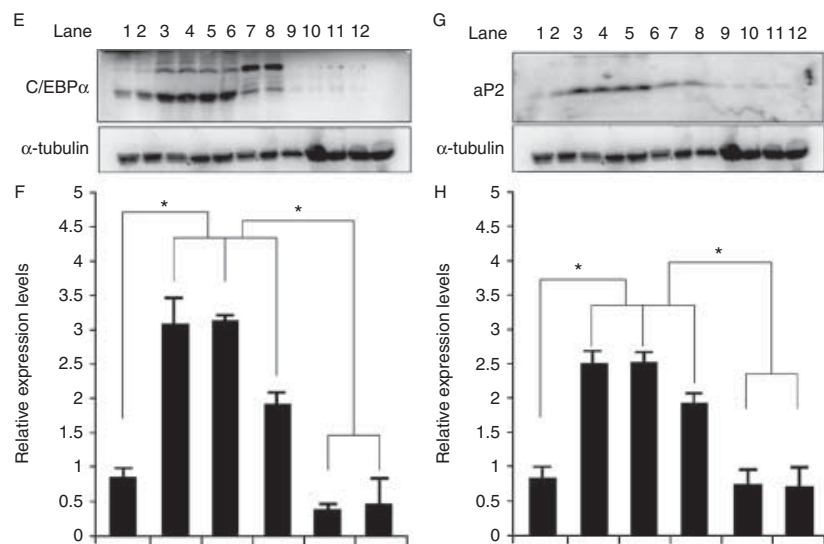

Figure 3

The effect of $E_{2}$ on the expression of adipogenesis marker genes of $P P A R \gamma$, $C / E B P \alpha$, and aP2 in fat tissue. The protein expression of S100A16 (A), PPAR $\gamma$ (B), $C / E B P \alpha(E)$, and aP2 (G) was analyzed with western blotting. (C, D, F and H) Relative expression of S100A16, PPAR $\gamma, C / E B P \alpha$, and aP2 based on grayscale analysis. $\alpha$-Tubulin was used as the control. Lanes 1 and 2 , normal

of abdominal fat are thought to promote insulin resistance (Ryan 2000, Soares et al. 2006), in our study, $\mathrm{E}_{2}$ treatment inhibited body weight and visceral fat gain, and alleviate insulin resistance. With regard to diet, we found that $\mathrm{E}_{2}$ improved glucose-stimulated insulin secretion in OVX rats under the chow and HFD conditions, and that it was beneficial for maintaining blood glucose homeostasis (Fig. 2). Moreover, $\mathrm{E}_{2}$ normalized the levels of TC, TG,

control rats on the chow diet; lanes 3 and 4, normal control rats on the HFD; lanes 5 and 6, OVX rats on the chow diet; lanes 7 and 8, OVX rats on the HFD; lanes 9 and 10, OVX rats treated with $E_{2}$ on the chow diet; lanes 11 and $12, \mathrm{OVX}$ rats treated with $\mathrm{E}_{2}$ on the HFD. Results are expressed as the mean \pm s.D. ${ }^{*} P<0.05$ compared with the corresponding control group.

and UA that had been increased in the OVX rats, under the chow and the HFD conditions. HDL and $\mathrm{Cr}$ displayed no changes, while LDH and ALT displayed no changes in the OVX rats but decreased in $\mathrm{E}_{2}$-treated rats (Tables 2 and 3). $\mathrm{E}_{2}$ treatment reduced lipid accumulation in the liver under both conditions (Fig. 1B). UA is an independent risk factor for metabolic syndrome. Our results showed that $\mathrm{E}_{2}$ loss in OVX rats obviously increase the level of UA whether under
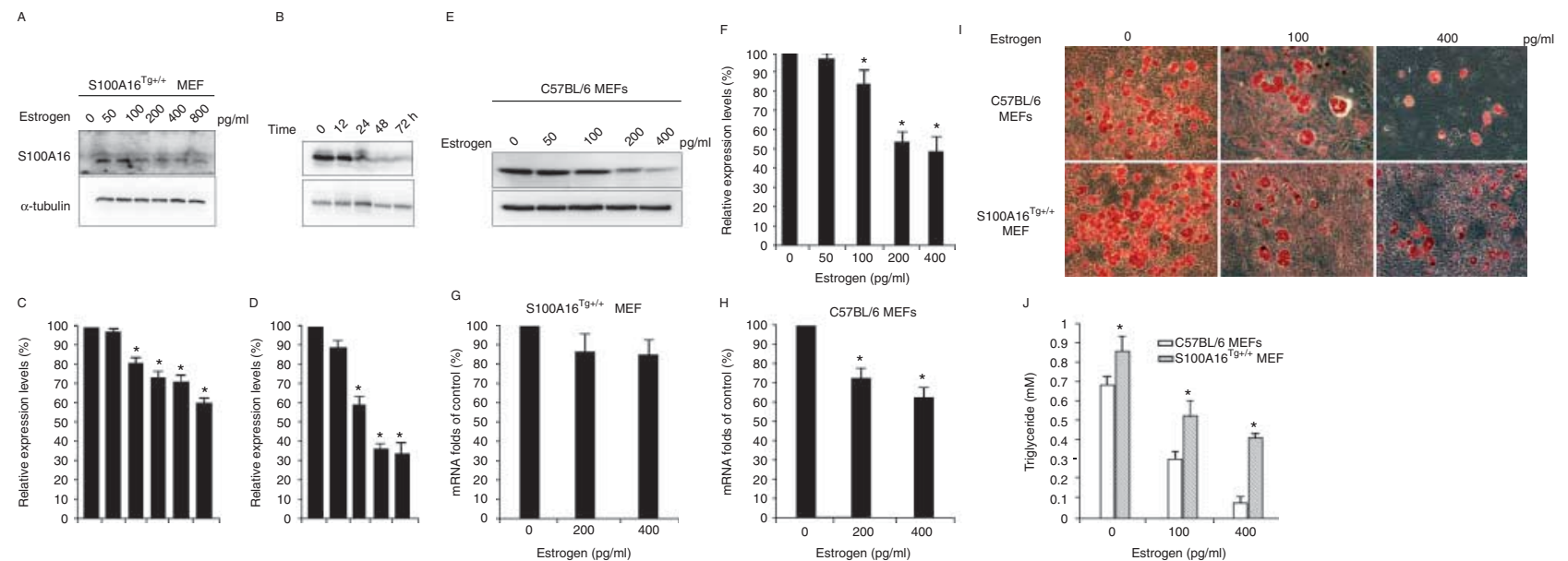

Figure 4

$E_{2}$-induced suppression of adipogenesis via S100A16 inhibition. (A) Western blot assays of S100A16 expression in the protein extracts collected from S100A $16^{\mathrm{Tg}+/+}$ MEFs treated with different concentrations of $E_{2}(0,50,100,200,400$, and $800 \mathrm{pg} / \mathrm{ml})$ for $24 \mathrm{~h}$. (B) Western blot assays of S100A16 expression in the protein extracts collected from S100A $16^{\mathrm{Tg}+/+}$ MEFs treated with $100 \mathrm{pg} / \mathrm{ml} \mathrm{E}_{2}$ for different times $(0,12,24,48$, and $72 \mathrm{~h}$ ). $\alpha$-Tubulin was used as the control. (E) Western blot assays of S100A16 expression in the protein extracts collected from C57BL/6 MEFs treated with different concentrations of $E_{2}(0,50,100,200$, and $400 \mathrm{pg} / \mathrm{ml})$ for $24 \mathrm{~h}$.

http://jme.endocrinology-journals.org DOI: 10.1530/JME-13-0273
(C) 2014 The authors Printed in Great Britain
(C, D and F) Relative expression of S100A16 based on grayscale analysis. (G and H) mRNA levels of S100A16 S100A16 ${ }^{\mathrm{Tg}+/+}$ MEFs and normal MEFs, respectively, treated with $E_{2}$. (I) Oil Red $O$ staining patterns for MEFs from C57BL/6 and S100A $16^{\mathrm{Tg}+/+}$ mice treated with different concentrations of $E_{2}$ and induced to differentiate into adipocytes. Photographs were taken under a light microscope with $200 \times$ magnification. (J) Triglyceride accumulation in the MEFs was significantly higher in the $5100 \mathrm{~A} 16^{\mathrm{Tg}+1+}$ MEFs for all $E_{2}$ concentrations. ${ }^{*} P<0.05$ compared with the corresponding control group.

Published by Bioscientifica Ltd 
A

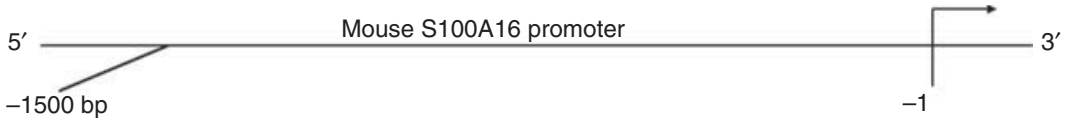

-180 ttcctctgccttgtcggattctgctcagagcctgtgggtttaggagggtggggttggggg $\begin{cases}-121 \\ \end{cases}$ TywGsTCmGr

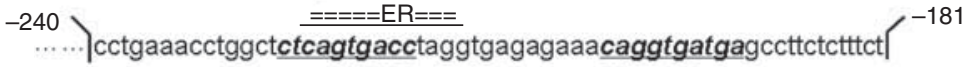

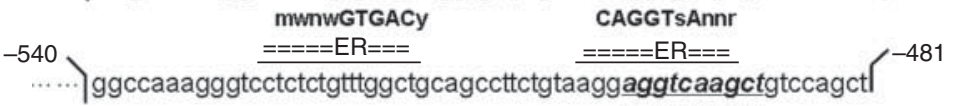

mGGTCAnnsT

B

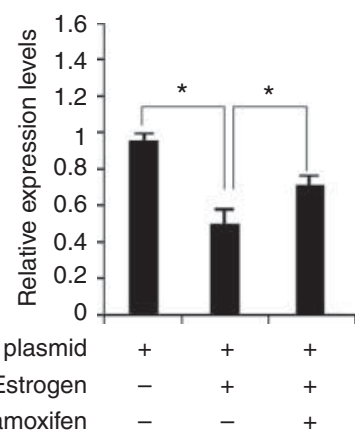

\section{Figure 5}

Inhibition of $\mathrm{S} 100 \mathrm{~A} 16$ transcription by $\mathrm{E}_{2}$. (A) The 1500-bp promoter region of S100A16 shows four estrogen receptor (ER) binding sites. (B) Results of the S100A16 luciferase reporter assay; S100A16 expression was reduced in

the chow conditions or under the HFD conditions, but $\mathrm{E}_{2}$ replacement therapy could reverse this phenomenon (Table 3).

Little is known about the molecular mechanism underlying $\mathrm{E}_{2}$-induced weight loss. This complex process is regulated by many cell signals. For example, $\mathrm{E}_{2}$ binding to ERs $(E R \alpha$ and $E R \beta)$ resulted in the initiation of signal transduction. $E_{2}$ may exert the effect of inhibiting body weight gain via leptin-like effects (Gao et al. 2007). In our previous study, we first found a new gene, S100A16, related to obesity, which is a member of the $S 100$ protein family (Liu et al. 2011). It is interesting that we found four EREs in the promoter of S100A16 within the 1500 bp by using AliBaba2 analysis (Fig. 5A). Therefore, we speculated that estrogen might regulate metabolism progress by mediating S100A16 expression. To verify this hypothesis, we examined the expression of S100A16 as well as the adipocyte marker genes $P P A R \gamma, C / E B P \alpha$, and $\mathrm{aP} 2$ in the fat tissues from the different groups of rats mentioned earlier. The results showed that $\mathrm{E}_{2}$ treatment inhibited the expression of adipocyte marker genes, including $P P A R \gamma$, $C / E B P \alpha$, and $\mathrm{aP2}$, and of S100A16 (Fig. 3), which was consistent with the previous studies (Alonso-Vale et al. the presence of $E_{2}$, and this effect was ameliorated by the addition of tamoxifen. Results are expressed as mean \pm s.D. *indicates statistical significance $(P<0.05)$.

2009, Yim et al. 2011). To further determine whether $\mathrm{E}_{2}$ acts via the regulation of S100A16 expression, MEFs were extracted from the S100A $16^{\mathrm{Tg}+/+}$ mice bred in our laboratory and incubated with $\mathrm{E}_{2}$ at different dosages and for different times, we found that the $\mathrm{E}_{2}$ inhibited S100A16 expression in a dose- and time-dependent manner (Fig. 4A, B, C and D). At the same time, we observed the role of $\mathrm{E}_{2}$ in the differentiation of MEFs extracted from S100A $16^{\mathrm{Tg}+/+}$ mice and control C57BL/6 mice by Oil Red $\mathrm{O}$ staining and TG determination. It was significant that S100A16 promoted the differentiation of MEFs and that $\mathrm{E}_{2}$ inhibited the effects of S100A16 (Fig. 4E and F). Results of the S100A16 luciferase reporter assay also showed that S100A16 expression was reduced in the presence of $E_{2}$, and this effect was ameliorated by the addition of tamoxifen (Fig. 5B).

So we think that estrogen might regulate metabolism by mediating S100A16 expression. Though many studies must be processed to reveal the molecular mechanisms of the effects of estrogen on metabolism via the S100A16 pathway. Indeed, our data showed that $\mathrm{E}_{2}$ inhibited adipogenesis and S100A16 expression, which indicates that $\mathrm{E}_{2}$ might decrease S100A16 expression by inhibiting

Published by Bioscientifica Ltd 
S100A16 gene transcription. Our study has revealed the interaction of S100A16 with estrogen, and will be applicable to clinical treatment involving estrogen.

\section{Declaration of interest}

The authors declare that there is no conflict of interest that could be perceived as prejudicing the impartiality of the research reported.

\section{Funding}

This work was supported by grants from the National Natural Science Foundation of China (grant numbers 81270952 and 81070684 ), the Jiangsu Province's Key Provincial Talents Program (BE 2011802), the Projects in the Jiangsu Science \& Technology Pillar Program (BE 2011802), the Project Funded by the Priority Academic Program Development of Jiangsu Higher Education Institutions, the Program for Development of Innovative Research Team in the First Affiliated Hospital of NJMU (number 20113012), and the Special Scientific Research Project from the Ministry of Health, China (grant number 201002002). Nanjing Medical University Science and Technology Development Foundation (2012NJMU122).

\section{Author contribution statement}

R Z, D S, and W Z conducted the molecular and the animal studies, carried out the data collection, and wrote this paper; $Y X, D L, M L, Q H$, and $Y Z$ conducted the animal studies; $A Z$ conducted part of the molecular studies; and $\mathrm{Y} L$ designed this study.

\section{References}

Alonso-Vale MI, Vernochet C, Farmer SR \& Lima FB 2009 Adipocyte differentiation is inhibited by melatonin through the regulation of C/EBP $\beta$ transcriptional activity. Journal of Pineal Research 47 221-227. (doi:10.1111/j.1600-079X.2009.00705.x)

Basu R, Campioni M, Basu A, Nair KS, Jensen MD, Khosla S, Klee G, Toffolo G, Cobelli C \& Rizza RA 2007 Two years of treatment with dehydroepiandrosterone does not improve insulin secretion, insulin action, or postprandial glucose turnover in elderly men or women. Diabetes $\mathbf{5 6}$ 753-766. (doi:10.2337/db06-1504)

Carr MC 2003 The emergence of the metabolic syndrome with menopause. Journal of Clinical Endocrinology and Metabolism 88 2404-2411. (doi:10. 1210/jc.2003-030242)

Ding EL, Manson JE, Rifai N, Buring JE \& Liu S 2007 Plasma sex steroid hormones and risk of developing type 2 diabetes in women: a prospective study. Diabetologia 50 2076-2084. (doi:10.1007/s00125007-0785-y)

Gao Q, Nie Y, Rao Y, Choi CS, Bechmann I, Leranth C, Toran-Allerand D, Priest CA, Roberts JL, Gao XB et al. 2007 Anorectic estrogen mimics leptin's effect on the rewiring of melanocortin cells and Stat3 signaling in obese animals. Nature Medicine 13 89-94. (doi:10.1038/nm1525)
Golden SH, Vaidya D, Szklo M, Gapstur S, Kopp P, Liu K \& Ouyang P 2007 Endogenous sex hormones and glucose tolerance status in postmenopausal women. Journal of Clinical Endocrinology and Metabolism 92 1289-1295. (doi:10.1210/jc.2006-1895)

Grabe N 2002 AliBaba2: context specific identification of transcription factor binding sites. In Silico Biology 2 S1-S15.

Hu FB \& Grodstein F 2002 Postmenopausal hormone therapy and the risk of cardiovascular disease: the epidemiologic evidence. American Journal of Cardiology 90 26F-29F. (doi:10.1016/S0002-9149(01)02219-6)

Kalish GM, Laughlin GA \& Gulanski BI 2003 Association of endogenous sex hormones and insulin resistance among postmenopausal women: results from the Postmenopausal Estrogen/Progestin Intervention Trial. Journal of Clinical Endocrinology and Metabolism 88 1646-1652. (doi:10.1210/jc.2002-021375)

Królik M \& Milnerowicz H 2012 The effect of using estrogens in the light of scientific research. Advances in Clinical and Experimental Medicine 21 535-543.

Liu Y, Zhang RH, Xin J, Sun Y, Li J, Wei D \& Zhao AZ 2011 Identification of S100A16 as a novel adipogenesis promoting factor in 3T3-L1 cells. Endocrinology 152 903-911. (doi:10.1210/en.2010-1059)

Manrique C, Habibi J, Mugerfeld I, Garro M \& Sowers JR 2012 Loss of estrogen receptor $\alpha$ signaling leads to insulin resistance and obesity in young and adult female mice. Cardiorenal Medicine 2 200-210. (doi:10.1159/000339563)

Nichols HB, Newcomb PA, Titus LJ, Egan KM, Hampton JM \& Visvanathan K 2012 Postoophorectomy estrogen use and breast cancer risk. Obstetrics and Gynecology 120 27-36. (doi:10.1097/AOG.0b013e31825a717b)

Rogers NH, Strissel KJ, Obin MS \& Greenberg AS 2009 Reduced energy expenditure and increased inflammation are early events in the development of ovariectomy-induced obesity. Endocrinology 150 2161-2168. (doi:10.1210/en.2008-1405)

Ryan AS 2000 Insulin resistance with aging: effects of diet and exercise. Sports Medicine 30 327-346. (doi:10.2165/00007256-200030050-00002)

Ryan AS, Nicklas BJ \& Berman DM 2002 Hormone replacement therapy, insulin sensitivity, and abdominal obesity in postmenopausal women. Diabetes Care 25 127-133. (doi:10.2337/diacare.25.1.127)

Soares DV, de Lima Oliveira Brasil RR, Lobo PM, Salles E, Coeli CM, Conceição FL \& Vaisman M 2006 Two years of growth hormone replacement therapy in a group of patients with Sheehan's syndrome. Pituitary 9 127-135. (doi:10.1007/s11102-006-9990-9)

Sørensen MB, Højgaard L \& Ottesen B 2001 Obesity and sarcopenia after menopause are reversed by sex hormone replacement therapy. Obesity Research 9 622-626. (doi:10.1038/oby.2001.81)

Stubbins RE, Holcomb VB, Hong J \& Núñez NP 2012 Oestrogen alters adipocyte biology and protects female mice from adipocyte inflammation and insulin resistance. Diabetes, Obesity \& Metabolism 14 58-66. (doi:10.1111/j.1463-1326.2011.01488.x)

Sutton-Tyrrell K, Santoro N, Lasley B, Sowers M, Johnston J, Mackey R \& Matthews K 2010 Reproductive hormones and obesity: 9 years of observation from the Study of Women's Health Across the Nation. American Journal of Epidemiology 171 1203-1213. (doi:10.1093/aje/ kwq049)

Yim MJ, Mizushina Y, Yoshida H, Saito Y \& Miyashita K 2011 Suppressive effects of amarouciaxanthin A on 3T3-L1 adipocyte differentiation through down-regulation of PPAR $\gamma$ and $\mathrm{C} / \mathrm{EBP} \alpha$ mRNA expression. Journal of Agricultural and Food Chemistry 59 1646-1652. (doi:10.1021/ jf103290f)

Received in final form 31 January 2014

Accepted 5 February 2014

Accepted Preprint published online 5 February 2014 http://jme.endocrinology-journals.org

DOI: 10.1530/JME-13-0273 (c) 2014 The authors Printed in Great Britain
Published by Bioscientifica Ltd 